\title{
Application of AXAFS Spectroscopy to Transition-Metal Oxides: Influence of the Nearest and Next Nearest Neighbour Shells in Vanadium Oxides**
}

\author{
Daphne E. Keller, Bert M. Weckhuysen,* and Diek C. Koningsberger*[a]
}

\begin{abstract}
The influence of changes in coordination number, interatomic distances, and oxidation state on the intensity and centroid position of the Fourier transform (FT) of the atomic X-ray absorption fine structure (AXAFS) peak of vanadium oxide bulk model compounds and aluminasupported vanadium oxide clusters has been investigated. Using $\mathrm{Na}_{3} \mathrm{VO}_{4}$ and $\mathrm{V}_{2} \mathrm{O}_{5}$ as model compounds, it has been shown that the nearest neighbour shells have a pronounced influence on the
\end{abstract}

\begin{abstract}
AXAFS intensity; specifically, a $40 \%$ decrease in intensity was observed between these two compounds. Secondly, the influence of partial reduction of the vanadium oxide species has been determined; this led to a $50 \%$ decrease in the AXAFS intensity and to an in-
\end{abstract}

Keywords: AXAFS spectroscopy • metal-support interactions • solidstate structures - supported catalysts $\cdot$ vanadium oxides crease in the centroid position. Furthermore, the influence of the vanadium oxide loading has been assessed. A non-linear relationship between the vanadium oxide loading and the AXAFS intensity has been found, indicating that the AXAFS intensity is sensitive to the formation of $\mathrm{V}-\mathrm{O}-\mathrm{V}$ bridging bonds between the vanadium $\mathrm{VO}_{4}$ clusters. The results show that AXAFS can be used to probe the relative energy level of the vanadium valence orbitals.

\section{Introduction}

Many parameters affect the catalytic properties of transition-metal oxide catalysts, for example, metal oxide loading, pre-treatment conditions, molecular structure, electronic structure, and the nature of the supporting oxide. ${ }^{[1-7]}$ Various researchers have investigated the activities and selectivities of metal oxide catalysts. However, little is known about the parameters that are truly responsible for the catalytic action of transition-metal oxides.

To study the effect of the support on the catalytic performance, one has to find a tool that is capable of probing the influence of the local environment (e.g., the support or promoters) on the properties of the catalytically active species, that is, a metal particle or metal oxide cluster. Metal-

[a] Dr. D. E. Keller, Prof. Dr. B. M. Weckhuysen,

Prof. Dr. D. C. Koningsberger

Inorganic Chemistry and Catalysis Group

Department of Chemistry, Utrecht University

P.O. Box 80083, 3508 TB Utrecht (The Netherlands)

Fax: $(+31) 30-251-1027$

E-mail: b.m.weckhuysen@chem.uu.nl d.c.koningsberger@chem.uu.nl

[**] AXAFS: atomic X-ray absorption fine structure.

Supporting information for this article is available on the WWW under http://www.chemeurj.org/ or from the author. (oxide)-support interactions can be ascribed to a structural (particle/cluster size and shape) effect, but can also have an electronic origin. For supported metal particles, the effect of the support on the catalytic properties has been determined by several techniques, for example, XPS, FT-IR analysis of adsorbed CO, and newly developed delta XANES and atomic XAFS (AXAFS) techniques. ${ }^{[8-15]}$ In particular, the application of AXAFS has, in our opinion, led to a better understanding of metal-support interaction effects. ${ }^{[8,15-17]}$

AXAFS is sensitive to changes in the potential around the X-ray absorbing atom. The potential field around an atom is mainly determined by the first and second coordination spheres. O'Grady et al. have shown for $\mathrm{Pt} / \mathrm{Ru}$ alloys that the AXAFS intensity changes systematically with the composition of the alloy. ${ }^{[18]}$ Thus, when the number of $\mathrm{Ru}$ atoms around a $\mathrm{Pt}$ atom increases, the intensity of the FT AXAFS peak increases and the peak centroid shifts to lower values of $R$. Comparison of these effects with the effects observed for a Pt electrode as a function of the applied voltage suggests that the first coordination shell of the Pt in the $\mathrm{Pt} / \mathrm{Ru}$ alloy influences the electronic properties (interatomic potential) of the $\mathrm{Pt}$ atom. ${ }^{[18,19]}$ The effect of changes in the coordination around the absorber atom has been further illustrated for Pt by van Dorssen et al., who compared the AXAFS of a Pt foil with that of bulk $\mathrm{Na}_{2} \mathrm{Pt}(\mathrm{OH})_{6}$. The AXAFS intensity was found to be significantly higher in the 
case of $\mathrm{Na}_{2} \mathrm{Pt}(\mathrm{OH})_{6}$ and the peak position was shifted to lower values of $R$. The increase in intensity is due to the fact that the $\mathrm{Pt}-\mathrm{O}$ bond length in $\mathrm{Na}_{2} \mathrm{Pt}(\mathrm{OH})_{6}$ is shorter than the $\mathrm{Pt}-\mathrm{Pt}$ bond length in the foil, which results in more interaction between the $\mathrm{Pt}$ absorber atom and the scatterer oxygen atoms. ${ }^{[20]}$ The influence of bond length on the position and intensity of the AXAFS peak has been thoroughly discussed by Wende et al. ${ }^{[21]}$ They showed that for oxygen atoms on a $\mathrm{Cu}$ surface, a shorter $\mathrm{Cu}-\mathrm{O}$ distance caused the AXAFS peak to appear at lower values of $R$ with increased intensity. ${ }^{[21]}$

The effect on the AXAFS of next nearest neighbours, that is, atoms two or more shells removed from the absorber atom, has been investigated for organometallic systems and for ions in aqueous solutions. ${ }^{[22-24]}$ Tromp et al. have shown that for para-substituted NCN-pincer $\mathrm{Pt}$ complexes, the AXAFS of Pt varies with the nature of the substituent. An electron-donating substituent $\left(\mathrm{NH}_{2}\right)$ results in a higher AXAFS intensity than an electron-withdrawing substituent $(\mathrm{COOH})$, and the peak centroid shifts to lower values of $R$ for the electron-withdrawing substituent. ${ }^{[22,23]}$ The influence of neighbouring atoms over a longer range has been demonstrated for $\mathrm{Zn}(\mathrm{OH})_{4}{ }^{2-}$ ions in basic solution. The interaction between the zincate ion and surrounding hydrated cations causes dramatic changes in the AXAFS as a result of changes in the $\mathrm{Zn}-\mathrm{M}$ distances and cation electronegativity. ${ }^{[24]}$

AXAFS has also been applied to probe the influence of supporting oxides (zeolites and amorphous mesoporous supports) on the electronic properties of $\mathrm{Pt}$ and $\mathrm{Pd}$ particles. ${ }^{[8,10,14,15,25]}$ In these studies, metal nanoparticles of similar sizes were used to separate metal particle size effects from support effects. ${ }^{[25]}$ It has been shown with AXAFS that the influence of the support is exerted through changes in the electron density on the support oxygen atoms when the support composition is altered. ${ }^{[10]}$ The complete density of states (DOS) of the Pt is shifted to higher binding energy, and the location of the $6 \mathrm{~s}, \mathrm{p}$ interstitial bonding orbital (IBO) moves from the surface to the metal-support interface of the Pt particles with decreasing ionicity of the support $^{1}$ (with decreasing electronic charge on the oxygen atoms of the support). ${ }^{[26]}$ The variations in support oxygen charge density are often the result of promotion effects or alterations in the support cations (e.g., Si/Al ratio), and so these are next nearest neighbour effects. ${ }^{[8,15]}$

The results mentioned above for bulk metal systems, organometallic systems, and supported metal catalysts have shown that AXAFS is a viable tool for probing the influence of the local surroundings on the electronic properties of a central atom. Although the presence of an AXAFS contribution in the X-ray absorption data of oxide systems has been established, ${ }^{[20,27]}$ to the best of our knowledge, no systematic study of the influence of the chemical surroundings,

\footnotetext{
${ }^{1}$ Ionicity of the support (definition as used in AXAFS-related papers): the effective electron density on the support oxygen atoms. High ionicity results in electron-rich oxygen atoms. ${ }^{[8]}$
}

including the effect of the support, on the AXAFS of small metal oxide clusters has yet been carried out.

In the present work, three case studies have been used to determine the influence of changes in the first and next nearest neighbour shells on the AXAFS of vanadium bulk reference compounds and alumina-supported vanadium oxide clusters. In particular, the effects of oxidation/reduction treatments and vanadium oxide loading on the Fourier transform AXAFS peak (both intensity and centroid position) of alumina-supported vanadium oxide clusters have been determined. Using atomic XAFS, it has been possible to differentiate the effects of the formation of formal chemical bonds between $\mathrm{VO}_{4}$ clusters from the sole presence of isolated neighbouring $\mathrm{VO}_{4}$ clusters.

\section{Results}

Background subtraction; isolation of the AXAFS oscillations from the atomic background: Isolation of the AXAFS oscillations from the atomic background may be complicated. The first shell contribution for vanadium oxide samples is found at a much shorter distance than for Pt nanoparticles. Consequently, overlap between the EXAFS, AXAFS, and possibly other contributions such as double-electron excitations $(\mathrm{DEE})^{[22,23]}$ or Ramsauer-Townsend features $(\mathrm{RTR})^{[20]}$ makes the analysis much more difficult. This complicates the isolation of the AXAFS and EXAFS contributions from the background. The presence of DEE or RTR in the raw data cannot be excluded. When a systematic method for background subtraction is used, the AXAFS can be reliably and reproducibly isolated from the atomic background.

The background subtraction procedure is illustrated in Figure 1. For all samples, the starting point of the background was chosen at the lowest possible energy after the edge. It is very important that the start point is not so low that the background starts to follow the edge shape, since purely isolated atomic contributions to the spectrum are incorporated into the final $\chi(\mathrm{k})$ obtained after background subtraction. For the alumina samples, this means that the background is started after the first small feature after the edge rise.

The need for a continuously adjustable smoothing parameter (SM) is shown in Figure $1 \mathrm{a}$ and $\mathrm{d}$ for $\mathrm{Na}_{3} \mathrm{VO}_{4}$ and $1 \mathrm{~V}$ Al-D ( $1 \mathrm{wt} \% \mathrm{~V}_{2} \mathrm{O}_{5}$ on $\mathrm{Al}_{2} \mathrm{O}_{3}$, after dehydration), respectively. The peak intensities of the main EXAFS peak and the AXAFS peak, as well as the intensity of the FT at $R=0 \AA$, were determined for a series of different SM parameters. Obviously, the value of SM has a significant effect on the peak intensities. The SM parameter was varied in increments of 0.1 around a suitable value of about 10 for $1 \mathrm{~V}$-AlD. In this case, a variation in the SM parameter of roughly $1 \%$ is required to find the optimal value. In the case of $\mathrm{Na}_{3} \mathrm{VO}_{4}$, a variation in the SM parameter of about 0.5 around a suitable value of 19.5 was required. The resulting Fourier transforms of the EXAFS functions are shown in 

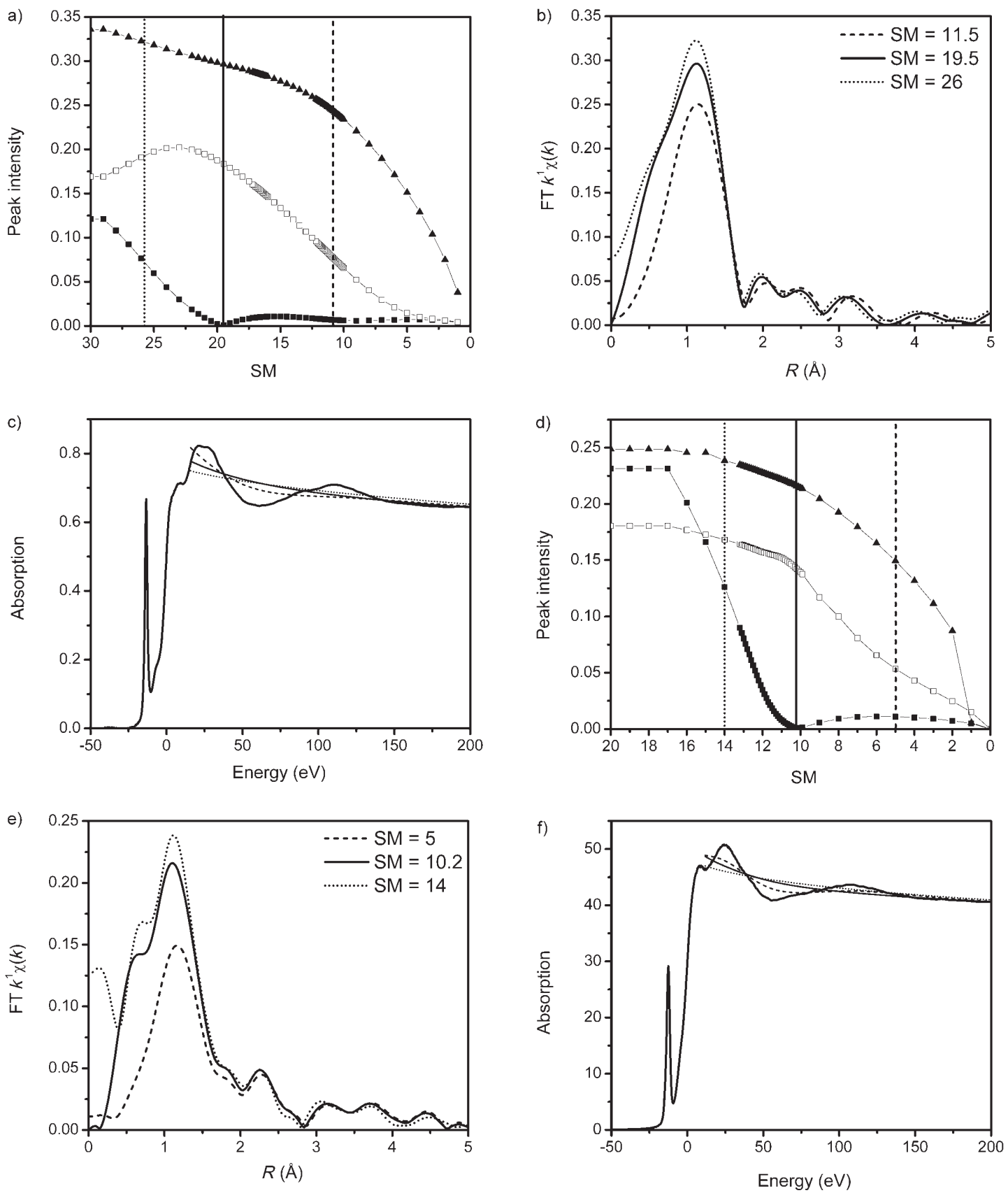

Figure 1. Intensity of the main EXAFS peak at $R=1.2 \AA$, and of the AXAFS peak at $R=0.7 \AA$ and at $R=0 \AA$ as a function of the smoothing parameter (SM) for a) $\mathrm{Na}_{3} \mathrm{VO}_{4}$ and b) $1 \mathrm{~V}$-Al-D. The SM criterion used in this work is indicated by a vertical solid line. Fourier transforms for three different SM values, indicated by the solid (correctly smoothed), dashed (undersmoothed), and dotted (oversmoothed) vertical lines for c) $\mathrm{Na}_{3} \mathrm{VO} \mathrm{O}_{4}$ and $\mathrm{d}$ ) $1 \mathrm{~V}$ - $\mathrm{Al}-\mathrm{D}$. The resulting backgrounds for three $\mathrm{SM}$ values for e) $\mathrm{Na}_{3} \mathrm{VO}_{4}$ and f) $1 \mathrm{~V}$-Al-D.

Figure $1 \mathrm{~b}$ and e at three different SM values: one oversmoothed (dotted line), one at the correct SM value (solid line), and one undersmoothed (dashed line). The oversmoothed spectra show considerable intensity at $R=0 \AA$. The undersmoothed spectra show distinctly lower intensities for the EXAFS main peak and the AXAFS peak. The corresponding backgrounds at the different SM factors are shown in Figure 1c and $\mathrm{f}$. The correct value of the SM parameter is indicated by a minimum value of the FT at $R=$
$0 \AA$ and a maximum intensity of the EXAFS and AXAFS contributions, as indicated by the solid line in Figure 1b and e.

Determining the influence of the nearest and next nearest neighbours on the AXAFS of bulk and supported vanadium oxide species: three case studies: To determine the AXAFS contribution to the XAFS spectrum, the EXAFS part has to be eliminated from the spectrum through fitting of the data. 
The fitting results and an extensive discussion thereof are provided in the Supporting Information. Table 1 provides a summary of the fitting results (interatomic distances and coordination numbers), together with the catalyst codes used throughout this paper. Details of the preparation and pretreatment of the catalysts are provided in the Experimental Section.

Table 1. Sample codes together with a summary of the EXAFS fit results.

\begin{tabular}{|c|c|c|c|c|}
\hline $\begin{array}{l}\text { Sample } \\
\text { code }\end{array}$ & Sample & & $\mathrm{N}^{[\mathrm{a}]}$ & $\begin{array}{l}R \\
{[\AA]^{[\mathrm{b}]}}\end{array}$ \\
\hline $\mathrm{Na}_{3} \mathrm{VO}_{4}$ & bulk $\mathrm{Na}_{3} \mathrm{VO}_{4}$ & $\mathrm{~V}-\mathrm{O}_{(1)}$ & 4 & 1.70 \\
\hline \multirow[t]{5}{*}{$\mathrm{V}_{2} \mathrm{O}_{5}$} & bulk $\mathrm{V}_{2} \mathrm{O}_{5}$ & $\mathrm{~V}=\mathrm{O}_{(1)}$ & 1 & 1.58 \\
\hline & & $\mathrm{V}-\mathrm{O}_{(2)}$ & 1 & 1.779 \\
\hline & & $\mathrm{V}-\mathrm{O}_{(3)}$ & 2 & 1.878 \\
\hline & & $\mathrm{V}-\mathrm{O}_{(4)}$ & 1 & 2.017 \\
\hline & & $\mathrm{V} \cdots \mathrm{O}_{(5)}$ & 1 & 2.790 \\
\hline \multirow[t]{6}{*}{ 1V-Al-D } & $\begin{array}{l}1 \mathrm{wt} \% \mathrm{~V}_{2} \mathrm{O}_{5} / \mathrm{Al}_{2} \mathrm{O}_{3} \text { after dehydra- } \\
\text { tion }\end{array}$ & $\mathrm{V}=\mathrm{O}_{(1)}$ & 1 & 1.58 \\
\hline & & $\mathrm{V}-\mathrm{O}_{(2)}$ & 3 & 1.72 \\
\hline & & $\mathrm{V} \cdots \mathrm{O}_{(3)}$ & 1 & 2.29 \\
\hline & & $\mathrm{V} \cdots \mathrm{Al}_{(4)}$ & 1 & 3.09 \\
\hline & & $\mathrm{V} \cdots \mathrm{O}_{(5)}$ & 2 & 3.50 \\
\hline & & $\mathrm{V} \cdots \mathrm{O}_{(6)}$ & 2 & 4.32 \\
\hline \multirow[t]{3}{*}{ 1V-Al-R } & $1 \mathrm{wt} \% \mathrm{~V}_{2} \mathrm{O}_{5} / \mathrm{Al}_{2} \mathrm{O}_{3}$ after reduction & $\mathrm{V}=\mathrm{O}_{(1)}$ & 0.67 & 1.58 \\
\hline & & $\mathrm{V}-\mathrm{O}_{(2)}$ & 2.11 & 1.71 \\
\hline & & $\mathrm{V}-\mathrm{O}_{(3)}$ & 1.87 & 1.98 \\
\hline \multirow[t]{7}{*}{$5 \mathrm{~V}-\mathrm{Al}$} & $5 \mathrm{wt} \% \mathrm{~V}_{2} \mathrm{O}_{5} / \mathrm{Al}_{2} \mathrm{O}_{3}$ & $\mathrm{~V}=\mathrm{O}_{(1)}$ & 0.96 & 1.58 \\
\hline & & $\mathrm{V}-\mathrm{O}_{(2)}$ & 3.02 & 1.72 \\
\hline & & $\mathrm{V} \cdots \mathrm{O}_{(3)}$ & 1.03 & 2.10 \\
\hline & & $\mathrm{V} \cdots \mathrm{O}_{(4)}$ & 1.00 & 2.36 \\
\hline & & $\mathrm{V} \cdots \mathrm{Al}_{(5)}$ & 0.93 & 3.07 \\
\hline & & $\mathrm{V} \cdots \mathrm{V}_{(6)}$ & 1.07 & 3.50 \\
\hline & & $\mathrm{V} \cdots \mathrm{O}_{(7)}$ & 0.97 & 2.91 \\
\hline \multirow[t]{7}{*}{$10 \mathrm{~V}-\mathrm{Al}$} & $10 \mathrm{wt} \% \mathrm{~V}_{2} \mathrm{O}_{5} / \mathrm{Al}_{2} \mathrm{O}_{3}$ & $\mathrm{~V}=\mathrm{O}_{(1)}$ & 0.96 & 1.58 \\
\hline & & $\mathrm{V}-\mathrm{O}_{(2)}$ & 3.02 & 1.72 \\
\hline & & $\mathrm{V} \cdots \mathrm{O}_{(3)}$ & 1.05 & 2.70 \\
\hline & & $\mathrm{V} \cdots \mathrm{Al}_{(4)}$ & 0.95 & 3.16 \\
\hline & & $\mathrm{V} \cdots \mathrm{V}_{(5)}$ & 1.16 & 2.95 \\
\hline & & $\mathrm{V} \cdots \mathrm{O}_{(6)}$ & 0.99 & 3.20 \\
\hline & & $\mathrm{V} \cdots \mathrm{O}_{(7)}$ & 2.38 & 3.45 \\
\hline \multirow[t]{7}{*}{$20 \mathrm{~V}-\mathrm{Al}$} & $20 \mathrm{wt} \% \mathrm{~V}_{2} \mathrm{O}_{5} / \mathrm{Al}_{2} \mathrm{O}_{3}$ & $\mathrm{~V}=\mathrm{O}_{(1)}$ & 0.96 & 1.58 \\
\hline & & $\mathrm{V}-\mathrm{O}_{(2)}$ & 3.01 & 1.71 \\
\hline & & $\mathrm{V} \cdots \mathrm{O}_{(3)}$ & 1.11 & 2.67 \\
\hline & & $\mathrm{V} \cdots \mathrm{Al}_{(4)}$ & 0.95 & 3.16 \\
\hline & & $\mathrm{V} \cdots \mathrm{V}_{(5)}$ & 2.05 & 2.95 \\
\hline & & $\mathrm{V} \cdots \mathrm{O}_{(6)}$ & 0.99 & 3.20 \\
\hline & & $\mathrm{V} \cdots \mathrm{O}_{(7)}$ & 4.08 & 3.56 \\
\hline
\end{tabular}

[a] N: coordination number. [b] $R$ : interatomic distance.

Case I: Bulk oxides: $\mathrm{Na}_{3} \mathrm{VO}_{4}$ and $\mathrm{V}_{2} \mathrm{O}_{5}$ : The structures of $\mathrm{Na}_{3} \mathrm{VO}_{4}$ and $\mathrm{V}_{2} \mathrm{O}_{5}$ are well known from XRD data. Their known structural parameters were used to obtain a fit for the EXAFS data. The Fourier transform of the raw data and the best fit for $\mathrm{Na}_{3} \mathrm{VO}_{4}$ and $\mathrm{V}_{2} \mathrm{O}_{5}$ are presented in Figure 2a and $b$, respectively. Schematic structures with the resulting interatomic distances and coordination numbers are illustrated in Figure $2 \mathrm{c}$ and $\mathrm{d}$. An extensive discussion of the EXAFS data analysis is provided in the Supporting Information.

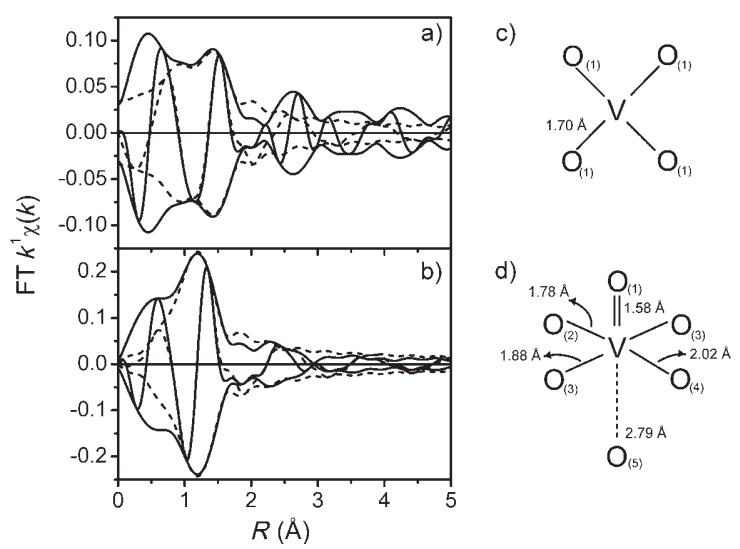

Figure 2. $k^{1}$-weighted Fourier transforms of the experimental $\chi(k)$ (solid line) and the final fit (dashed line) for a) $\mathrm{Na}_{3} \mathrm{VO}_{4}\left(\Delta \mathrm{k}=2.5-10 \AA^{-1}, \Delta R=\right.$ $0.8-1.5 \AA)$ and b) $\mathrm{V}_{2} \mathrm{O}_{5}\left(\Delta \mathrm{k}=2.5-10 \AA^{-1}, \Delta R=0.7-2.2 \AA\right)$. Schematic representations of the final fit results: c) $\mathrm{Na}_{3} \mathrm{VO}_{4}$ and d) $\mathrm{V}_{2} \mathrm{O}_{5}$.

The AXAFS contributions were obtained after subtraction of the final fit from the raw data. The Fourier transform of the residue $\left(k^{1}, \Delta k=2.5-8 \AA^{-1}\right)$, plotted from 0 to $1 \AA$ in Figure 3(a), shows separate AXAFS peaks for the two refer-

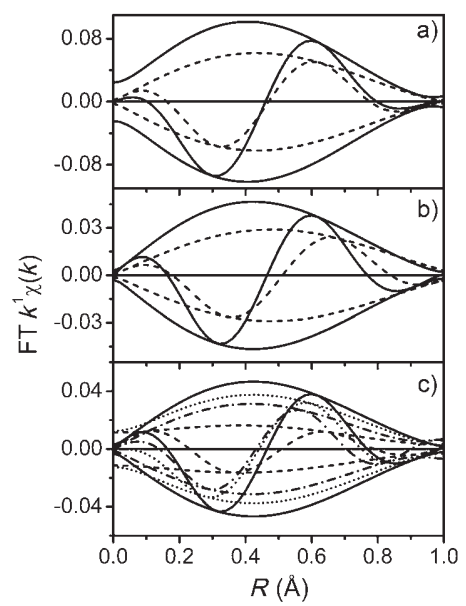

Figure 3. Residue (raw - total fit), $\Delta k=2.5-8 \AA^{-1}$, in the AXAFS region $\left(0<R<1 \AA\right.$ ) for a) $\mathrm{Na}_{3} \mathrm{VO}_{4}$ (solid line) and $\mathrm{V}_{2} \mathrm{O}_{5}$ (dashed line), b) $1 \mathrm{~V}$ Al-D (solid line) and $1 \mathrm{~V}-\mathrm{Al}-\mathrm{R}$ (dashed line) and c) $1 \mathrm{~V}$-Al (solid line), $5 \mathrm{~V}$-Al (dashed line), 10V-Al (dotted line), and 20V-Al (dot-dashed line).

ence compounds. It can be seen that the total potential field ${ }^{2}$ around the tetrahedrally coordinated vanadium in $\mathrm{Na}_{3} \mathrm{VO}_{4}$ leads to a much more intense AXAFS peak than that in the case of the square-pyramidal vanadium coordination in $\mathrm{V}_{2} \mathrm{O}_{5}$. The intensity increases from 0.062 to 0.101 and the centroid position shifts to slightly lower $R$ from $0.46 \AA$ to $0.43 \AA$, as listed in Table 2 . Obviously, the type (number

\footnotetext{
2 The total potential field depends on many parameters, including interatomic distances, symmetry, and coordination. The extent to which these parameters influence the AXAFS is dealt with in the Discussion section.
} 
Table 2. AXAFS intensity and centroid position as a function of vanadium coordination, vanadium oxide loading and pre-treatment conditions, together with average bond distances, coordination number, oxidation state, and number of $\mathrm{V} \cdots \mathrm{V}$ neighbours.

\begin{tabular}{lcccccccr}
\hline & $\mathrm{Na}_{3} \mathrm{VO}_{4}$ & $\mathrm{~V}_{2} \mathrm{O}_{5}$ & $1 \mathrm{~V}-\mathrm{Al}-\mathrm{D}$ & $1 \mathrm{~V}-\mathrm{Al}-\mathrm{R}$ & $1 \mathrm{~V}-\mathrm{Al}$ & $5 \mathrm{~V}-\mathrm{Al}$ & $10 \mathrm{~V}-\mathrm{Al}$ & $20 \mathrm{~V}-\mathrm{Al}$ \\
\hline $\mathrm{I}_{\mathrm{AXAFS}}$ & 0.101 & 0.062 & 0.047 & 0.026 & 0.047 & 0.016 & 0.038 & 0.031 \\
centroid position $[\AA]$ & 0.43 & 0.46 & 0.46 & 0.50 & 0.46 & 0.42 & 0.45 & 0.46 \\
$\left\langle R_{\mathrm{V}-\mathrm{O}}\right\rangle[\AA]$ & 1.70 & 1.83 & 1.678 & 1.796 & 1.678 & 1.678 & 1.678 & 1.678 \\
$\mathrm{CN}_{\mathrm{O}}$ & 4 & 5 & 4 & 4.6 & 4 & 4 & 4 & 4 \\
oxidation state & $5+$ & $5+$ & $5+$ & $<5+$ & $5+$ & $5+$ & $5+$ & $5+$ \\
$\mathrm{R}_{\mathrm{V}-\mathrm{V}}(\AA)$ & - & - & - & - & - & 3.5 & 2.95 & 2.95 \\
$\mathrm{CN}_{\mathrm{V}}$ & - & - & - & - & 0 & 1 & 1.16 & 2.05 \\
\hline
\end{tabular}

and distance) of nearest neighbour oxygen coordination has an influence on the AXAFS intensity and centroid position.

Case II: Low-loaded alumina-supported vanadium oxide under oxidizing and reducing conditions: $1 \mathrm{~V}-\mathrm{Al}-\mathrm{D}$ and $1 \mathrm{~V}$ $A l-R$ : The fit for $1 \mathrm{~V}-\mathrm{Al}-\mathrm{D}$ has been described in detail in previous papers by our group. ${ }^{[28]}$ The data could be fitted with a monomeric $\mathrm{VO}_{4}$ species with one $\mathrm{V}=\mathrm{O}$ bond, two $\mathrm{V}-$ $\mathrm{O}$ bonds, and one $\mathrm{V}-\mathrm{O}_{(\mathrm{b})}-\mathrm{M}_{\text {support }}$ bond. The fitting results are summarised in Figure $4 \mathrm{a}$ and $\mathrm{c}$, in which the Fourier transform of the raw data and the final fit are shown together with a schematic representation of the interatomic distances and the coordination numbers obtained from the fit. The differences between the $1 \mathrm{~V}-\mathrm{Al}-\mathrm{D}$ and $1 \mathrm{~V}-\mathrm{Al}-\mathrm{R}$ samples can clearly be seen in the Fourier transforms $\left(k^{1}, \Delta k=2.5\right.$ $11 \AA^{-1}$ ), which are plotted in Figure 4a and b. The obvious dissimilarities indicate a change in vanadium oxide structure upon reduction of the supported vanadium oxide with hydrogen.
Based on the results of XANES, Raman, UV/Vis, and ESR analyses, as presented in the Supporting Information, we tentatively assume that not all of the vanadium oxide clusters in $1 \mathrm{~V}-\mathrm{Al}-\mathrm{R}$ are reduced. This would imply that a mixture of the original dehydrated four-fold coordinated vanadium and reduced octahedrally coordinated vanadium is present in the hydrogen-treated vanadium oxide catalyst.

The fitting of the EXAFS data of the 1V-Al-R sample was based upon the assumption that a mixture of two different vanadium compounds was present in this reduced batch. The best fit was obtained with a mixture of $70 \%$ dehydrated $\mathrm{VO}_{4}$ and $30 \%$ reduced vanadium species and the Fourier transform of the best fit is shown in Figure 4b. The reduced species resembles the octahedrally coordinated $\mathrm{V}_{4} \mathrm{O}_{7}$, with six oxygen neighbours at an average distance of $1.98 \AA$. Schematic structures based upon the final fit results are depicted in Figure 4d. A full discussion of the EXAFS data analysis is provided in the Supporting Information.

The total fit was subtracted from the raw data resulting in the difference file. Fourier transformation of the difference file resulted in the AXAFS peaks (see Figure 3b). The AXAFS intensity decreases upon mild reduction of the vanadium oxide catalyst and the centroid position increases (see Table 2).
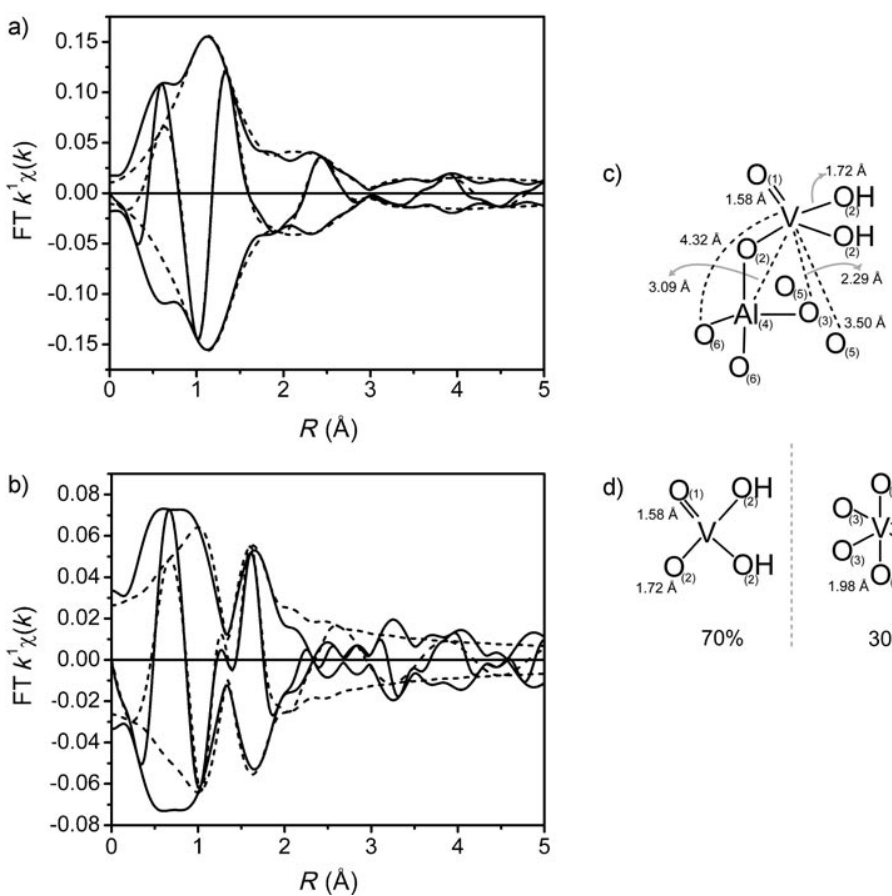

d)

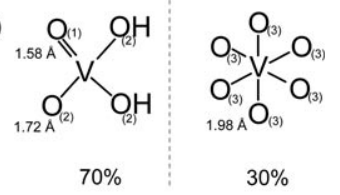

Figure 4. $k^{1}$-weighted Fourier transforms of the experimental $\chi(k)$ (solid line) and the total fit (dashed line). a) 1 V-Al-D $\left(\Delta k=2.5-11 \AA^{-1}, \Delta R=0.7-5.0 \AA\right)$ and b) $1 \mathrm{~V}-\mathrm{Al}-\mathrm{R}\left(\Delta \mathrm{k}=2.5-11 \AA^{-1}, \Delta R=0.7-2 \AA\right)$. Schematic representations of the final fit results: c) $1 \mathrm{~V}$-Al-D and d) $1 \mathrm{~V}$-Al-R (dehydrated $\mathrm{VO}_{4}$ left, reduced species right).
Case III: Influence of vanadium oxide loading: $5 \mathrm{~V}$-Al-D, $10 \mathrm{~V}-\mathrm{Al}-\mathrm{D}$ and 20V-Al-D: The influence of changes in the $\mathrm{V} \cdot \mathrm{V}$ coordination on the AXAFS was investigated by increasing the vanadium oxide loading of the alumina-supported catalysts. The Fourier transforms of the raw EXAFS data and the corresponding final fit $\left(k^{1}, \Delta \mathrm{k}=2.5-11 \AA^{-1}\right)$ are presented in Figure $5 \mathrm{a}-\mathrm{c}$. The region at higher values of $R$, in which $\mathrm{V} \cdots \mathrm{V}$ interactions are expected $(2.5<R<3 \AA)$, is different for each of the samples.

During the fitting process, which is discussed in detail in the Supporting Information, it became clear that the basic structure of each of the samples is made up of $\mathrm{VO}_{4}$ units. In $5 \mathrm{~V}$-Al-D, the $\mathrm{VO}_{4}$ unit is surrounded by other isolated 

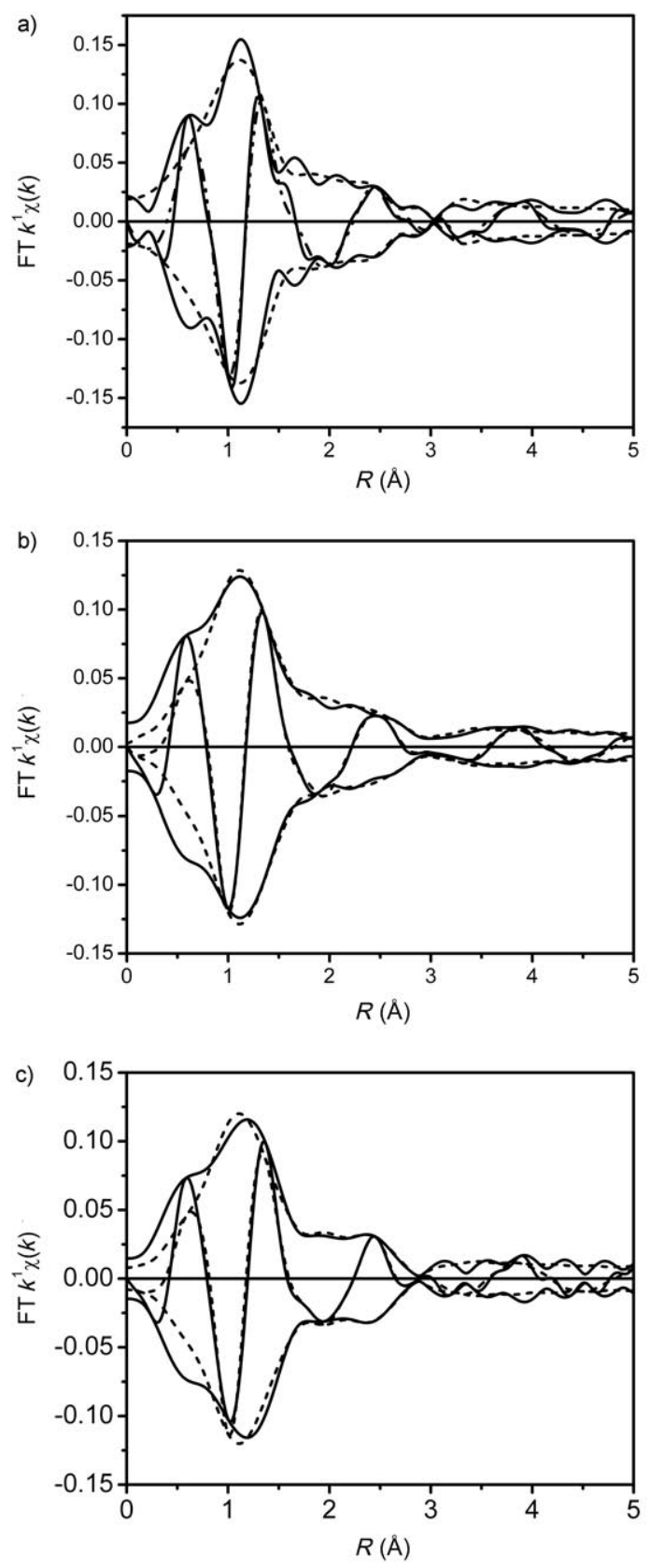

Figure 5. $k^{1}$-weighted Fourier transforms of the experimental $\chi(k)$ (solid line) and the total fit (dashed line) a) $5 \mathrm{~V}-\mathrm{Al}\left(\Delta k=2.5-11 \AA^{-1} ; \Delta R=0.7-4.0 \AA\right)$, b) $10 \mathrm{~V}-\mathrm{Al}\left(\Delta k=2.5-11 \AA^{-1}, \Delta R=0.7-4.0 \AA\right)$, and c) $20 \mathrm{~V}-\mathrm{Al}$ $\left(\Delta \mathrm{k}=2.5-11 \AA^{-1}, \Delta R=0.7-4.0 \AA\right)$. Schematic representations of the final fit results: d) $5 \mathrm{~V}$-Al and e) $10 \mathrm{~V}-\mathrm{Al}$ and $20 \mathrm{~V}$-Al. Terminal $\mathrm{H}$ atoms have been omitted for clarity. The distances denoted in this representation are shown as if the left vanadium atom is the absorber atom, meaning that $\mathrm{O}$ atoms at the same position within a $\mathrm{VO}_{4}$ cluster but belonging to the neighbouring cluster (at the right side of the diagram) have different $\mathrm{V} \cdots \mathrm{O}$ interatomic distances.

$\mathrm{VO}_{4}$ units at an average $\mathrm{V} \cdots \mathrm{V}$ distance of about $3.5 \AA$. With increasing vanadium oxide loading, chemical bonds are formed between the different $\mathrm{VO}_{4}$ units, resulting in a shorter average $\mathrm{V} \cdot \cdots \mathrm{V}$ distance of about $2.95 \AA$. Higher vanadium oxide loading also leads to a higher $\mathrm{V} \cdots \mathrm{V}$ coordination number, up to a maximum of two for 20V-Al-D. Schematic structures based upon the resulting EXAFS coordination parameters are presented in Figure 5d and e.
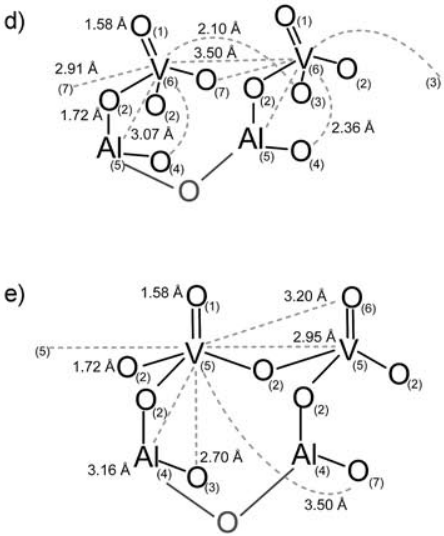

\section{Discussion}

Origin of AXAFS: In most cases, the oscillatory part $\chi_{\text {total }}(k)$ of XAFS is defined relative to an assumed smooth "atomic background" $\left(\mu_{\mathrm{a}}\right)$ : $\chi_{\text {total }}=\left(\mu_{\text {total }}-\mu_{\mathrm{a}}\right) / \mu_{\mathrm{a}}$. In principle, this results in a difference spectrum between a free absorber atom and an absorber atom in its chemical environment. However, the atomic background $\mu_{\mathrm{a}}$ is not necessarily smooth. It may contain features well above the absorption edge, including white lines, resonances, and jumps due to multi-electron transitions. Furthermore, the atomic background $\mu_{\mathrm{a}}$ may contain a fine structure itself, both in molecules and in condensed systems. This fine structure was first described by Holland et al. and is ascribed to the scattering of the outgoing electron wave on the edge of the embedded atom potential of the absorber atom. ${ }^{[29]}$ This effect is depicted schematically in Figure 6. Back-scattering of the photoelectron is resonant in nature. Thus, the back-scattering amplitude of the AXAFS is enhanced when the kinetic energy of the free photoelectron is equal to the energy of the vanadium valence orbitals. The atomic background can change when the potential around the absorber atom is altered through overlap with the potentials of neighbouring atoms causing the fine structure. The AXAFS features arise from the difference between the free absorber atom poten- 


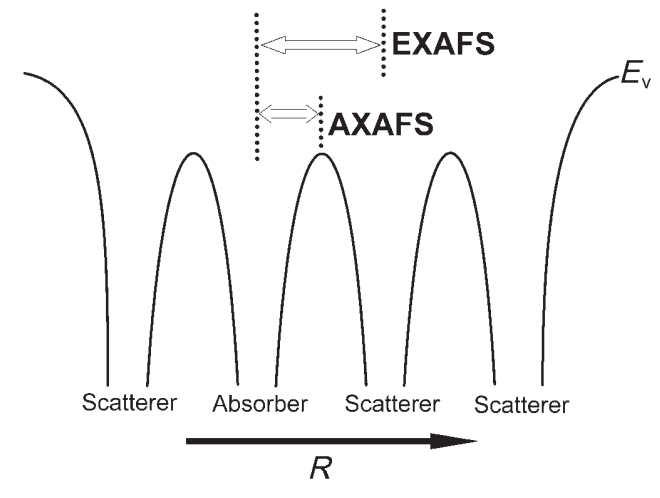

Figure 6. Schematic representation of the potentials surrounding an absorber atom. A photoelectron can scatter off the neighbouring atom potentials (EXAFS) and scatter on the edge of its own embedded atom potential (AXAFS)

tial and a changing embedded absorber atom potential. Thus, the atomic absorption $\mu_{\mathrm{a}}$ can be viewed as a combination of the atomic background of the free atom, that is, in vacuum $\left(\mu_{\text {free }}\right)$, and the AXAFS signal $\left(\chi_{\text {AXAFS }}\right): \mu_{\mathrm{a}}=\mu_{\text {free }}(1+$ $\left.\chi_{\text {AXAFS }}\right)$. When all contributions to the absorption spectrum are taken into account, the following expression for the total absorption coefficient can be defined: $\mu_{\text {total }}=\mu_{\text {free }}(1+$ $\left.\chi_{\text {AXAFS }}\right)\left(1+\chi_{\text {EXAFS }}\right)=\mu_{\text {free }}\left(1+\chi_{\text {total }}\right)$.

Background subtraction; isolation of the AXAFS oscillations from the atomic background: Previously, research has been focused on the complete removal of the "atomic background", that is, including the AXAFS, from the experimental data, resulting in the extraction of $\chi_{\text {EXAFs. }}$ The methods of background removal are based on either removal by established criteria or by iterative analysis. ${ }^{[30,31]}$ In neither case is the AXAFS part of the data in the same Fourier transform as the EXAFS part of the data, which makes it difficult to determine a relationship between the separate contributions to the X-ray absorption spectra. This implies that the AXAFS should be kept in $\chi_{\text {total }}$ instead of in the background.

When the iterative background subtraction method is used, detailed knowledge of the EXAFS part of the spectrum is presumed. In our case, however, we do not have detailed information on the exact vanadium oxide structure and support contributions to the spectrum prior to the background subtraction. Consequently, the background subtraction methods described above are not suitable for our system.

Another background subtraction method, previously described by Ramaker et al. for supported metal nanoparticles, is focused on the sole removal of $\mu_{\text {free }}$ from the data. ${ }^{[32]}$ This new method makes use of a continuously adjustable smoothing parameter (SM) to determine the best cubic spline background. ${ }^{[33]}$ The original method was based on three criteria, which are slightly adapted here for oxide systems:

1) The free-atom contribution, double-electron excitation (DEE), and the Ramsauer-Townsend reflection (RTR) at low $R(<0.3 \AA)$ have to be minimised; more specifically for the oxide systems, the FT has to tend towards zero at $R=0 \AA$.

2) The main EXAFS peak at $1.2 \AA$ and the AXAFS contribution at $R=0.7 \AA$ remain at the highest possible intensity.

3) This procedure is checked with $k^{1}$ and $k^{3}$ weighting for different $k$ ranges, including low $k$ values $(k=1.5 \AA)$. This ensures that no EXAFS $\left(\chi_{\mathrm{EXAFS}}\right)$ signal is removed from the data.

The signal that remains at low $R(0.7 \AA)$ is the difference between the scattering for the embedded atom and the free atom, that is, the AXAFS. The AXAFS has a long-wavelength oscillation and high amplitude at low $k$ values.

The method of background subtraction that has been used in the present work is not very different from the method described by Ramaker et al. ${ }^{[32]}$ Since the main EXAFS peak is at $1.2 \AA$ for vanadium oxide, a considerably shorter distance than the main peak in metal particles, the AXAFS, DEE, and RTR contributions are found at shorter distances as well. As a result, there is considerable overlap between the different peaks. This can be clearly observed for the EXAFS and AXAFS contribution in the FT, indicating that the separation of the different contributions to the spectrum is not easy. The clearest criterion is that the intensity has to be minimised at $R=0 \AA$, as is illustrated in Figure $1 \mathrm{a}$ and $\mathrm{d}$. It does not concern overlapping peaks; it just makes sure that no atomic background is incorporated into the final $\chi(k)$. Since the presence of DEE and RTR cannot be excluded and these contributions may influence the intensity of the peaks in the FT, it is important that background subtraction is performed consistently for all samples under investigation. A consistent background subtraction allows comparison of the AXAFS from different samples.

Parameters determining the potential and the FT AXAFS peak: The exact shape and energy level of the potential of the central vanadium atom is partly determined by the energy of its orbitals. ${ }^{[10]}$ The AXAFS is related to the orbital energy through the resonant scattering condition of the photoelectron, that is, the kinetic energy of the photoelectron is equal to the kinetic energy of the bound electron (only the deeper localised valence orbitals are relevant for the AXAFS scattering). ${ }^{[34]}$ The effects determining the FT AXAFS peak can be described using the muffin-tin approximation to approximate the embedded atom potential. Within the muffin-tin approximation, the potential is flat and zero in the interstitial region $\left(R>R_{\mathrm{mt}}\right)$ and otherwise equal to the sum of overlapping, spherically symmetrical potentials $\left(R<R_{\mathrm{mt}}\right)$. The average potential of all atoms at $R_{\mathrm{mt}}$ is $V_{\text {int }}$, which determines the zero energy level or the effective bottom of the conduction band. The FT AXAFS peak is then determined by the difference between the embedded atom potential $\left(V_{\mathrm{emb}}\right)$ and the truncated free atom potential $\left(V_{\mathrm{TFA}}\right),{ }^{[35]}$ which leads to the following mathematical description: $\left|\mathrm{FT}\left(k e^{-2 \mathrm{i} \delta} \chi_{\mathrm{AX}}\right)\right| \approx \Delta V \cdot \Gamma$. Since the potential of the em- 
bedded absorber atom is influenced by its direct surroundings, that is, the neighbouring atoms, four parameters can influence the electronic properties of the absorber atom.

1) The average distance to the surrounding atoms: this affects the interaction between the vanadium atom and its neighbours and thus alters the shape of the coulomb tail (i.e. roll-over).

2) The bond inductive effect, determined by the averaged electronic properties of the neighbouring atoms (e.g., electronegativity). Variations in the electronic properties of the neighbouring atoms lead to variations in $V_{\text {int }}$.

3) The coulomb effect, that is, variation in the electron density of the neighbouring oxygen atoms alters the coulomb tail (i.e. roll-over) of the neighbouring atom poten- tial and thus the potential of the vanadium atom. $V_{\text {int }}$ changes as well, since the overall potential of the surrounding oxygen atoms is altered.

4) Charge transfer to the vanadium atom. Charge transfer induces variation in the vanadium atomic potential, thereby causing changes in the roll-over and some variation in $V_{\text {int }}$.

The individual effects of each of these parameters on the FT AXAFS peak intensity and centroid position are illustrated in Figure 7a and b, although the changes in peak intensity and centroid position observed in the vanadium oxide systems described herein suggest that several of these parameters act at the same time. An increase in the average distance to the neighbouring atoms, without a change in $V_{\text {int }}$, a)

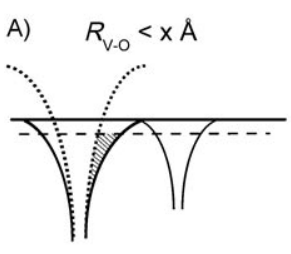

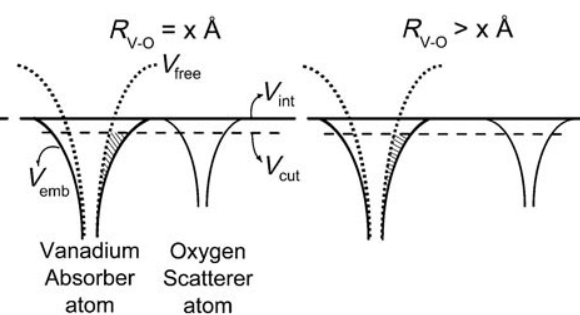
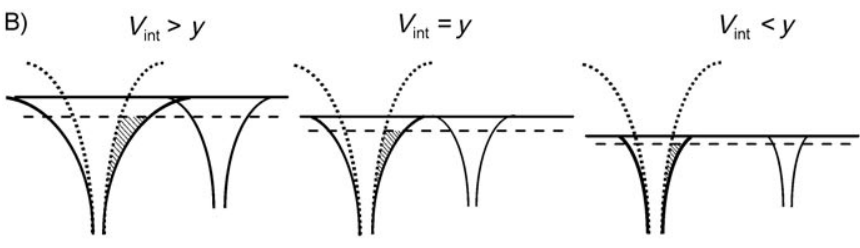

$\mathrm{O}$

C)

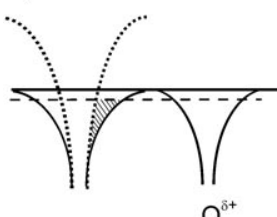

$\mathrm{O}^{8+}$

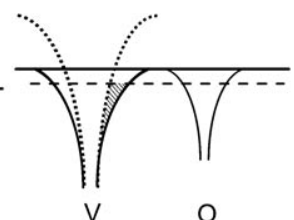

$\mathrm{O}$

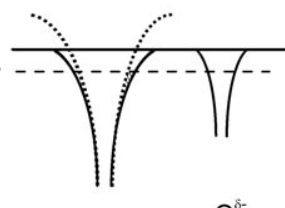

$\mathrm{O}^{\delta-}$
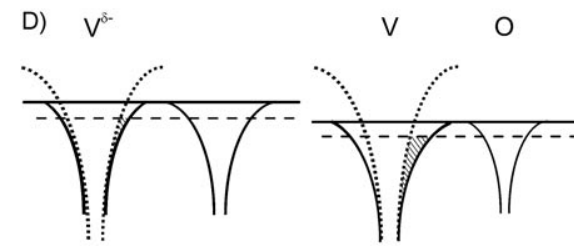

$\mathrm{V}^{8+}$

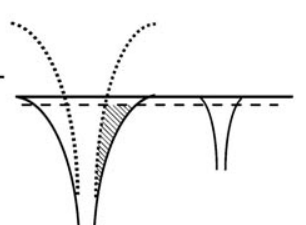

b)

A)

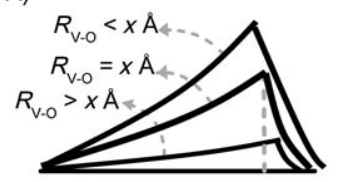

B)

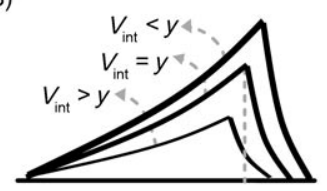

C)

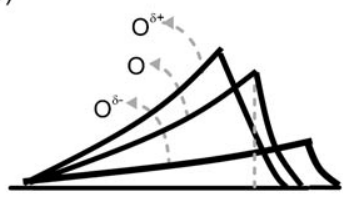

D)

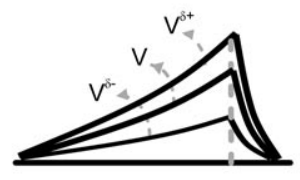

Figure 7. Illustration of the effect of the average bond distance, the bond inductive effect, the coulomb effect, and charge transfer on the AXAFS intensity and centroid position. Each effect is illustrated separately, as if it were acting alone at a certain moment. a) Potential wells and b) corresponding AXAFS for different situations: A) The average bond length ( $R, x \AA$ denotes an arbitrary value for the average bond length): An increase in the average distance to neighbouring atoms, without a change in $V_{\text {int }}$, results in an decrease in AXAFS intensity since the decreased interaction is expressed in a smaller coulomb tail. A small increase in the centroid position $\left(R_{\text {centroid }}\right)$ is observed. B) The bond inductive effect ( $V_{\text {int }}, y$ denotes an arbitrary value of $\left.V_{\text {int }}\right)$ : a decrease in $V_{\text {int }}$ results in a lower AXAFS intensity and a decrease in $R_{\text {centroid }}$ C) The coulomb effect: Small changes in charge on the surrounding oxygen atoms cause the oxygen potential to change. A slightly more positive oxygen atom $\left(\mathrm{O}^{\delta+}\right)$ has a broader potential since the binding energy is lower. The corresponding longer range coulomb tail and the simultaneous decrease in $V_{\text {int }}$ result in a higher AXAFS intensity and a decrease in $R_{\text {centroid }}$. D) The charge transfer effect: A slightly more negative vanadium atom $\left(\mathrm{V}^{\delta-}\right)$ as a result of charge transfer has a more narrow potential since the binding energy is higher and $V_{\text {int }}$ increases. The corresponding shorter range coulomb tail results in a smaller AXAFS intensity and no change in $R_{\text {centroid }}{ }^{[10]}$ 
results in a decrease in FT AXAFS peak intensity since the decreased interaction is expressed in a smaller coulomb tail. A small increase in the centroid position $\left(R_{\text {centroid }}\right)$ is observed (Figure 7A). When $V_{\text {int }}$ is lowered, the FT AXAFS peak intensity decreases and $R_{\text {centroid }}$ decreases as well (Figure 7B). Small variations in the charge on the surrounding oxygen atoms lead to variation in the oxygen potential. A slightly more positive oxygen atom $\left(\mathrm{O}^{\delta+}\right)$ has a broader potential since the binding energy is lower. The corresponding long-range coulomb tail and the simultaneous decrease in $V_{\text {int }}$ result in a higher FT AXAFS peak intensity and a decrease in $R_{\text {centroid }}$ (Figure 7C). A slightly more negative vanadium atom $\left(\mathrm{V}^{\delta-}\right)$ as a result of charge transfer has a narrower potential since the binding energy is higher and $V_{\text {int }}$ increases. The corresponding shorter range coulomb tail results in a smaller FT AXAFS peak intensity and no change in $R_{\text {centroid }}$ (Figure 7D). ${ }^{[10]}$

Influence of changes in the nearest and next nearest neighbour coordinations on the FT AXAFS peak: The origin of changes in the AXAFS intensity and centroid position can be straightforward. In many cases, however, a two-fold or three-fold approach is needed to explain the observed effects. Although it may be possible to determine a dominant effect in some of the cases discussed below, one has to be aware of the fact that the changes in the AXAFS intensity and the centroid position due to this effect may not explain the observed trends. This is simply because either the AXAFS intensity or the centroid position may move in the opposite direction to that expected on the basis of the dominant effect (see Figure 7). In the following, we attempt to combine the data from AXAFS spectroscopy with known or measured structural data to determine the parameters that play a role in the AXAFS of vanadium oxide species.

Oxygen coordination: Table 2 summarises the changes in the FT AXAFS peak together with relevant parameters for the samples under investigation. Comparing the AXAFS for $\mathrm{V}_{2} \mathrm{O}_{5}$ with that for $\mathrm{Na}_{3} \mathrm{VO}_{4}$, a decrease in intensity and a small increase in the centroid position are observed (Figure 3a). The oxidation state of the vanadium atoms is the same, so the difference in AXAFS cannot be attributed to a change in the number of electrons in the vanadium $\mathrm{d}$ orbitals. The small increase in the centroid position can only be explained by an increase in $V_{\text {int }}$, which is probably caused by the change in the number of oxygen neighbours (from four to five) and their relative position with respect to the central vanadium atom. An increase in $V_{\text {int }}$ should also result in an increase in the AXAFS intensity. However, the intensity decreases, implying that the change in $V_{\text {int }}$ is not the only effect determining the AXAFS in this case. The intensity increase caused by the change in $V_{\text {int }}$ is compensated, indeed overcompensated, by a decrease in the roll-over of the potential. This decrease may be attributed to a diminished interaction between the vanadium atom and the surrounding oxygen atoms as a result of a longer average $\mathrm{V}-\mathrm{O}$ bond distance: $1.70 \AA$ for $\mathrm{Na}_{3} \mathrm{VO}_{4}$ and $1.83 \AA$ for $\mathrm{V}_{2} \mathrm{O}_{5}$.
Average oxidation state: Upon (partial) reduction, the AXAFS intensity decreases and the centroid position moves to higher values of $R$ (Figure $3 \mathrm{~b}$ ). The increased centroid position can again only be explained in terms of an increase in $V_{\text {int }}$. This increase in $V_{\text {int }}$ is caused by both the change in average oxidation state and the change in the number and position of the neighbouring oxygen atoms. The expected accompanying increase in AXAFS intensity may be partially compensated by the decrease in roll-over. This decrease in roll-over results from both the increase in the average $\mathrm{V}-\mathrm{O}$ distance (from $1.678 \AA$ to $1.796 \AA$ ) and the lowering of the average oxidation state of the central vanadium atom. The lower oxidation state moves the potential well of the vanadium upwards, diminishing its width at the truncation position, thereby explaining the decrease in AXAFS intensity.

Vanadium oxide loading: With an increasing amount of vanadium oxide on the support surface, no alteration in the first oxygen coordination shell is observed. Both the coordination number and the average bond distance remain the same for all of the samples under investigation. The oxidation state is also the same $\left(\mathrm{V}^{5+}\right)$ for all of the samples. The AXAFS intensity and centroid position, however, are clearly affected by the vanadium oxide loading (Figure 3c). An initial decrease in both intensity and centroid position is observed for $5 \mathrm{~V}$-Al, which is followed by an increase in these parameters when the loading is further increased $(10 \mathrm{~V}-\mathrm{Al}$ and 20V-Al), as summarised in Table 2.

A V $\cdots \mathrm{V}$ coordination appears in the EXAFS when the vanadium oxide loading is increased. Both the $\mathrm{V} \cdots \mathrm{V}$ distance and the coordination number are a function of the vanadium oxide loading. The observation of a much larger $\mathrm{V} \cdot \cdot \mathrm{V}$ distance for the $5 \mathrm{~V}$-Al sample may account for the dip in intensity and centroid position. The distance is too large for the formation of a $\mathrm{V}-\mathrm{O}-\mathrm{V}$ bridge, which implies that the change in the AXAFS is the result of a more elaborate mechanism (see Figure 8). The lower centroid position is the result of a decreased $V_{\text {int }}$ value. At $5 \mathrm{wt} \%$ vanadium oxide loading, the alumina surface is almost entirely covered with monomeric vanadium oxide clusters. These clusters may alter the properties of the support material, that is, the electron density of the support oxygen atoms, and thus influence the other vanadium oxide clusters by way of a promoter-like mechanism. A lower centroid position is caused by a decrease in $V_{\text {int }}$ and a decreased intensity is presumably caused by a decline in the roll-over. These effects can only be ex-

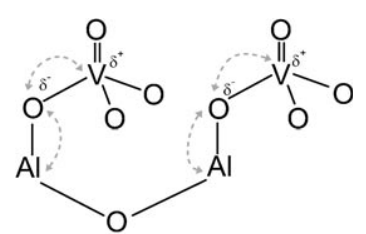

Figure 8. Mechanism of the influence of a neighbouring $\mathrm{VO}_{4}$ unit on the electron density of support oxygen atoms and vanadium atoms. Since one cluster influences the other and vice versa, the arrows indicating the direction of interaction are drawn in both directions. 
plained when a combination of two mechanisms is considered: changes in the electron densities of both the support oxygen atoms and the central vanadium atom. An increase in the oxygen electron density $\left(\mathrm{O}^{\delta-}\right)$ results in a smaller rollover and a higher $V_{\text {int }}$ value. Consequently, $\mathrm{O}^{\delta-}$ accounts for an increase in centroid position and a decline in AXAFS intensity. Thus, the alteration in the FT of the AXAFS is indeed not solely determined by the electron density of the support oxygen. A decrease in electron density on the vanadium atom itself $\left(\mathrm{V}^{\delta+}\right)$ results in a lower $V_{\text {int }}$ and a decrease in the roll-over. When these effects are operative at the same time, the roll-over will diminish considerably whereas there will be competition between the two opposing effects on $V_{\text {int }}$. The net result is a lowering of $V_{\text {int }}$ and a decreased roll-over, effects that are manifested in a substantially lower AXAFS intensity and a centroid position at a lower value of $R$.

When the loading is increased further, increases in both the AXAFS intensity and the centroid position are observed. The $\mathrm{V} \cdots \mathrm{V}$ bond length of $2.95 \AA$ for the $10 \mathrm{~V}-\mathrm{Al}$ sample implies the formation of a $\mathrm{V}-\mathrm{O}-\mathrm{V}$ bridge in this case. As a result, the neighbouring vanadium atom can directly influence the central vanadium atom through this bridge. This implies a diminished influence of the support on the electronic properties of the vanadium. Again, a combination of at least two mechanisms is needed to explain the resulting AXAFS. Presumably, the bridging oxygen has a slightly lower electron density $\left(\mathrm{O}^{\delta+}\right)$, resulting in a lower $V_{\text {int }}$ and increased roll-over. Concomitantly, the electron density on the vanadium increases compared to that in the case of $5 \mathrm{~V}-\mathrm{Al}$, thereby causing a higher $V_{\text {int }}$ value and larger roll-over.

The last step is the formation of multiple layers of vanadium oxide at $20 \mathrm{wt} \%$, that is, not all vanadium oxide clusters are in direct contact with the support material because a polymeric monolayer is exceeded (Table 3 ). In this case, the intensity of the AXAFS decreases a little, while the centroid position increases further. Less influence of the support results in a decrease in $V_{\text {int }}$ and less roll-over. However, a $\mathrm{V}-$ $\mathrm{O}-\mathrm{V}$ bond is still present, which causes a higher $V_{\text {int }}$ and a larger roll-over. The net result of these opposing effects is again a larger $V_{\text {int }}$ and slightly less roll-over.

AXAFS spectroscopy as a tool to probe changes in the energy level of the vanadium valence orbitals: In principle, AXAFS can be used to probe the energy level of the vanadium valence orbitals, as has been shown for the d-band position in metal particles. ${ }^{[10]}$ For vanadium oxide species, it has been found that a combination of two or more changing parameters is needed to explain the variations in the AXAFS. In several situations, the changes in AXAFS intensity and centroid position have only been explicable by assuming changes in the potential well of the vanadium atom, that is, changes in the energy level of the valence orbitals of vanadium. However, it may be difficult to distinguish between different effects, since coordination numbers and distances also play an important role.

\section{Conclusion}

The effect of the nearest and next nearest neighbouring atoms on the AXAFS of vanadium has been determined for both bulk and supported vanadium oxide species. Using $\mathrm{Na}_{3} \mathrm{VO}_{4}$ and $\mathrm{V}_{2} \mathrm{O}_{5}$ as model compounds, it was shown that the first shell oxygen coordination number and distances have a pronounced influence on the AXAFS intensity; specifically, a $40 \%$ decrease in intensity was observed between these two compounds. Secondly, the influence of partial reduction of the vanadium oxide species has been determined; this resulted in a $50 \%$ decrease in intensity and an increase in centroid position because of a higher electron density on the vanadium atom. Furthermore, the influence of the vanadium oxide loading has been investigated. A nonlinear relationship between loading and AXAFS intensity was found, indicating that AXAFS is sensitive to both the formation of a monomeric monolayer and the formation of $\mathrm{V}-\mathrm{O}-\mathrm{V}$ bridging bonds between the $\mathrm{VO}_{4}$ clusters at higher loadings. Moreover, AXAFS is related to the relative energy level of the vanadium valence orbitals, and this has been shown to change as a function of the nearest and next nearest neighbours.

AXAFS can be useful in determining the electronic properties of vanadium oxide species. It can provide information on the relative energy levels of the vanadium valence orbitals, which may sometimes be linked to the exact energy level. It may be difficult to distinguish between the different effects that are operative and isolation of the AXAFS signal is not always straightforward. However, a means of ranking vanadium oxide species on the basis of their electronic properties may prove useful in several fields, not least in catalysis.

\section{Experimental Section}

Catalyst preparation: The $\mathrm{Al}_{2} \mathrm{O}_{3}$-supported vanadium oxide catalysts were prepared using $\gamma-\mathrm{Al}_{2} \mathrm{O}_{3}$ (prepared in-house, $S_{\mathrm{BET}}=165 \mathrm{~m}^{2} \mathrm{~g}^{-1}$, $V_{\text {pore }}=0.35 \mathrm{mLg}^{-1}$ ). The $\mathrm{Al}_{2} \mathrm{O}_{3}$ support was prepared by the sol-gel method. ${ }^{[36]}$ The series of catalysts was prepared by incipient wetness impregnation with an $\mathrm{NH}_{4} \mathrm{VO}_{3}$ (Merck, p.a.) solution with oxalic acid (Brocacef, $99.25 \%$ pure). Table 3 contains some physicochemical properties of the catalysts under investigation, together with the catalyst code names 
used throughout this paper. The catalysts were dried for one night at room temperature and then for one night at $393 \mathrm{~K}$ and thereafter they were calcined at $773 \mathrm{~K}$ for $3 \mathrm{~h}$. This resulted in a series of catalysts with loadings ranging from $0.43 \mathrm{VO}_{x}$ per $\mathrm{nm}^{2}$ to $10.9 \mathrm{VO}_{x}$ per $\mathrm{nm}^{2}$.

Oxidation and reduction treatments: The dehydration (D) and reduction (R) pre-treatments to which $1 \mathrm{~V}$-Al was subjected were carried out in a special cell with quartz windows that enabled Raman measurements at room temperature under a controlled atmosphere. ${ }^{[37]}$ The dehydration pre-treatment was performed at $723 \mathrm{~K}$ in pure $\mathrm{O}_{2}\left(40 \mathrm{mLmin}^{-1}\right)$ for $3 \mathrm{~h}$. The catalyst pre-treated in this way is denoted as $1 \mathrm{~V}-\mathrm{Al}-\mathrm{D}$ in this paper. The reduction pre-treatment was performed after the dehydration pretreatment. Prior to the reduction treatment, the sample was flushed with $\mathrm{N}_{2}\left(90 \mathrm{mLmin}^{-1}\right)$ at $723 \mathrm{~K}$ for $30 \mathrm{~min}$; it was then reduced at $723 \mathrm{~K}$ for $30 \mathrm{~min}$ in a $10 \% \mathrm{H}_{2} / \mathrm{N}_{2}$ flow of $100 \mathrm{~mL} \mathrm{~min}^{-1}$. The hydrogen pre-treated catalyst is denoted as $1 \mathrm{~V}-\mathrm{Al}-\mathrm{R}$ in this paper. In the EXAFS cell, the dehydration pre-treatment was carried out at $623 \mathrm{~K}$ in a $2.5 \% \mathrm{O}_{2} / \mathrm{He}$ flow for $2 \mathrm{~h}$ and the reduction pre-treatment was performed after the dehydration treatment at $723 \mathrm{~K}$ for $30 \mathrm{~min}$ in a $10 \% \mathrm{H}_{2} / \mathrm{He}$ flow $\left(100 \mathrm{~mL} \mathrm{~min}^{-1}\right)$. The sample compartment was flushed with $\mathrm{He}$ for $15 \mathrm{~min}$ prior to the reduction. All more highly loaded catalysts were dehydrated at $623 \mathrm{~K}$ in a $2.5 \% \mathrm{O}_{2} / \mathrm{He}$ flow for $2 \mathrm{~h}$.

Raman and UV/Vis diffuse reflectance spectroscopic measurements: A special cell with quartz windows was used to permit Raman measurements on the $1 \mathrm{~V}$-Al pre-treated samples. The Raman spectrum (exposure time $50 \mathrm{~s} ; 50$ accumulations) was collected at room temperature using a Kaiser RXN spectrometer equipped with a $532 \mathrm{~nm}$ diode laser. A 5.5“ non-contact objective was used for beam focusing and collection of the scattered radiation.

$\mathrm{UV} / \mathrm{Vis}$ diffuse reflectance spectra of $1 \mathrm{~V}$-Al in the range $200-2200 \mathrm{~nm}$ were measured at room temperature after the pre-treatments using a Varian Cary 500 UV-Vis-NIR spectrometer. This set-up was equipped with a diffuse reflectance accessory, which was set to collect diffuse reflected light only. The spectrum was scanned with an averaging time of $0.1 \mathrm{~s}$, a data interval of $1 \mathrm{~nm}$, and a scan rate of $600 \mathrm{~nm} \mathrm{~min}^{-1}$. Baseline correction was performed by using a white Halon standard.

XAFS spectroscopy: XAFS experiments on the alumina-supported vanadium oxide catalysts were carried out at beamline E4 in Hasylab (Hamburg, Germany) using an $\mathrm{Si}(111)$ monochromator. The measurements were performed in fluorescence mode, using an ion chamber filled with 400 mbar $\mathrm{N}_{2}$ to determine $\mathrm{I}_{0}$. The detector was a seven-element solidstate (SiLi) detector. The monochromator was detuned to $80 \%$ of the maximum intensity at the $\mathrm{V} \mathrm{K}$ edge $(5465 \mathrm{eV})$ to minimize the presence of higher harmonics. The measurements were carried out on samples in an in situ cell with Kapton windows. Details of the cell design can be found elsewhere. ${ }^{[38]}$ Data were collected from the $1 \mathrm{~V}$-Al samples at $77 \mathrm{~K}$ after dehydration and reduction pre-treatments and those from four scans were averaged. The more highly loaded catalysts were analysed after dehydration treatment at $77 \mathrm{~K}$ and typically one scan was used for analysis.

EXAFS data analysis was carried out using the XDAP protocol developed by Vaarkamp et al. ${ }^{[39]}$ The background was subtracted employing cubic spline routines with a continuously adjustable smoothing parameter. ${ }^{[34]}$ This led to the normalised oscillatory part of the XAFS data, for which all contributions to the spectrum, including the AXAFS, were maximised. ${ }^{[34]}$

The EXAFS data analysis program XDAP allows one to perform multiple-shell fitting in $R$-space by minimising the residuals between both the absolute and the imaginary part of the Fourier transforms of the data and the fit. $R$-space fitting has important advantages compared to the usually applied fitting in $k$-space and is extensively discussed in a paper by Koningsberger et al. ${ }^{[34]}$ All contributions were fitted simultaneously in $R$-space with concomitant inspection of the FT of the difference file and calculated fit of each individual contribution. The difference file technique was applied in conjunction with phase-corrected Fourier transforms to resolve the different contributions to the EXAFS data. ${ }^{[34]}$ The fit was evaluated in all weightings ( $k^{n}$ with $n=0,1,2$, and 3 ) to unravel antiphase behaviour, which can easily lead to the non-detection of a particular contribution when only one particular weighting is used..$^{[34,40,41]}$ Details of the fitting procedure in relation to supported vanadium oxides have been described in previous papers by our group. ${ }^{[28,34]}$

Cerius ${ }^{2}$ structural model: A structural model of the $\mathrm{VO}_{4}$ unit on the $\gamma$ $\mathrm{Al}_{2} \mathrm{O}_{3}$ surface was produced using Cerius ${ }^{2}$ molecular modelling software. ${ }^{[42]}$ The $\gamma-\mathrm{Al}_{2} \mathrm{O}_{3}$ crystal was built up from X-ray diffraction data obtained and interpreted by Zhou et al. ${ }^{[43]}$ Subsequently, this crystal was cut along the (110) plane to expose the preferentially exposed surface; that is, the D layer according to the LEIS measurements performed by Stobbe-Kreemers et al. ${ }^{[44]}$

To create a structural model for supported monomeric vanadium oxide, a $\mathrm{VO}_{4}$ moiety was attached to the $\mathrm{Al}_{2} \mathrm{O}_{3}$ surface. The distances of the $\mathrm{V}=$ $\mathrm{O}_{(1)}$ and $\mathrm{V}-\mathrm{O}_{(2)}$ coordinations of the $\mathrm{VO}_{4}$ unit, as found in the EXAFS analysis, were used as input parameters for the Cerius ${ }^{2}$ molecular modelling program. The coordination numbers and distances of the $\mathrm{V}-\mathrm{O}_{(3)}$ and $\mathrm{V}-\mathrm{Al}_{(4)}$ higher coordination shells, as found in the EXAFS analysis, were taken as structural constraints. Rotation of the $\mathrm{VO}_{4}$ unit about the $\mathrm{Al}_{\text {support }}-\mathrm{O}_{(2)}$ bond and bending of the $\mathrm{V}-\mathrm{O}_{(2)}-\mathrm{Al}_{\text {support }}$ bond were the only operations performed to find a configuration that fitted the EXAFS data. The atoms of the $\mathrm{Al}_{2} \mathrm{O}_{3}$ support were kept fixed at all times. More highly loaded vanadium oxide catalysts ( 5 to $20 \mathrm{wt} \%$ ) were initially mimicked by adding monomeric species on adjacent aluminium atoms, with the $\mathrm{V} \cdots \mathrm{V}$ distance from the EXAFS analysis as an additional constraint This resulted in a model based on closely associated monomers and incorporating $\mathrm{V}-\mathrm{O}-\mathrm{V}$ bridges. The final higher-shell EXAFS fits for the dehydrated samples were determined after several iteration steps starting from the molecular model obtained by means of Cerius ${ }^{2}$

[1] B. M. Weckhuysen, D. E. Keller, Catal. Today 2003, 78, 25-46.

[2] G. Deo, I. E. Wachs, J. Catal. 1994, 146, 323-333.

[3] B. Olthof, A. Khodakov, A. T. Bell, E. Iglesia, J. Phys. Chem. B 2000, 104, 1516-1528.

[4] M. A. Bañares, Catal. Today 1999, 51, 319-348.

[5] L. J. Burcham, I. E. Wachs, Catal. Today 1999, 49, 467-484.

[6] M. A. Bañares, M. V. Martínez-Huerta, X. Gao, J. L. G. Fierro, I. E. Wachs, Catal. Today 2000, 61, 295-301.

[7] X. Gao, I. E. Wachs, Top. Catal. 2002, 18, 243-250.

[8] B. L. Mojet, J. T. Miller, D. E. Ramaker, D. C. Koningsberger, J. Catal. 1999, 186, 373-386

[9] C. Montes, M. E. Davis, B. Murray, M. Narayana, J. Phys. Chem. 1990, 94, 6431-6435.

[10] D. C. Koningsberger, J. de Graaf, B. L. Mojet, D. E. Ramaker, J. T. Miller, Appl. Catal. A 2000, 191, 205-220.

11] E. V. Benvenutti, L. Franken, C. C. Moro, Langmuir 1999, 15, 8140 8146.

[12] C. Roth, N. Benker, T. Burhmester, M. Mazurek, M. Loster, H. Fuess, D. C. Koningsberger, D. E. Ramaker, J. Am. Chem. Soc. 2005 , 127, 14607-14615.

[13] M. K. Oudenhuijzen, J. A. van Bokhoven, J. T. Miller, D. E. Ramaker, D. C. Koningsberger, J. Am. Chem. Soc. 2005, 127, 1530-1540.

[14] A. M. J. van der Eerden, T. Visser, T. A. Nijhuis, Y. Ikeda, M. Lepage, D. C. Koningsberger, B. M. Weckhuysen, J. Am. Chem. Soc 2005, 127, 3272-3273

[15] T. Visser, T. A. Nijhuis, A. M. J. van der Eerden, K. Jenken, Y. Ji, W. Bras, S. Nikitenko, M. Lepage, B. M. Weckhuysen, J. Phys. Chem. B 2005, 109, 3822-3831.

[16] D. E. Ramaker, G. E. van Dorssen, B. L. Mojet, D. C. Koningsberger, Top. Catal. 2000, 10, 157-165.

[17] D. E. Ramaker, J. de Graaf, J. A. R. van Veen, D. C. Koningsberger, J. Catal. 2001, 203, 7-17.

[18] W. E. O'Grady, X. Qian, D. E. Ramaker, J. Phys. Chem. B 1997, $101,5624-5626$

[19] W. E. O'Grady, D. E. Ramaker, Electrochim. Acta 1998, 44, 1283 1287.

[20] G. E. van Dorssen, D. C. Koningsberger, D. E. Ramaker, J. Phys. Condens. Matter 2002, 14, 13529-13541. 
[21] H. Wende, C. Litwinski, A. Scherz, T. Gleitsmann, Z. Li, C. Sorg, K. Baberschke, A. Ankudinov, J. J. Rehr, C. Jung, J. Phys. Condens. Matter 2003, 15, 5197-5206.

[22] M. Tromp, J. A. van Bokhoven, M. Q. Slagt, R. J. M. Klein Gebbink, G. van Koten, D. E. Ramaker, D. C. Koningsberger, J. Am. Chem. Soc. 2004, 126, 4090-4091.

[23] M. Tromp, M. Q. Slagt, R. J. M. Klein Gebbink, G. van Koten, D. E. Ramaker, D. C. Koningsberger, Phys. Chem. Chem. Phys. 2004, 6, 4397-4406.

[24] D. E. Ramaker, X. Qian, W. E. O'Grady, Chem. Phys. Lett. 1999, 299, 221-226.

[25] Y. Ji, A. M. J. van der Eerden, V. Koot, P. J. Kooyman, J. D. Meeldijk, B. M. Weckhuysen, D. C. Koningsberger, J. Catal. 2005, 234, 376-384.

[26] M. K. Oudenhuijzen, J. A. van Bokhoven, D. E. Ramaker, D. C. Koningsberger, J. Phys. Chem. B 2004, 108, 20247-20254.

[27] J. J. Rehr, C. H. Booth, F. Bridges, S. I. Zabinski, Phys. Rev. B 1994 , 49, $12347-12350$.

[28] a) D. E. Keller, F. M. F. de Groot, D. C. Koningsberger, B. M. Weckhuysen, J. Phys. Chem. B 2005, 109, 10223-10233; b) D. E. Keller, S. M. K. Airaksinen, A. O. Krause, B. M. Weckhuysen, D. C. Koningsberger, J. Am. Chem. Soc. 2007, 129, 3189-3197.

[29] B. W. Holland, J. B. Pendry, R. F. Pettifer, J. Bordas, J. Phys. C 1978 11, 633 .

[30] G. G. Li, F. Bridges, G. S. Brown, Phys. Rev. Lett. 1992, 68, 1609.

[31] W. H. Press, B. P. Flack, S. A. Teukolsky, W. T. Vetterling, Numerical Recipes in $C$, Cambridge University Press, Cambridge, 1989.

[32] D. E. Ramaker, B. L. Mojet, D. C. Koningsberger, W. E. O'Grady, J. Phys. Condens. Matter 1998, 10, 8753-8770.

[33] J. W. Cook, D. E. Sayers, J. Appl. Phys. 1981, 52, 5024.

[34] D. C. Koningsberger, B. L. Mojet, G. E. van Dorssen, D. E. Ramaker, Top. Catal. 2000, 10, 143-155.
[35] $V_{\mathrm{TFA}}$ is the free atom potential truncated by $V_{\text {cut }} . V_{\text {cut }}$ is defined as: $V_{\text {cut }}=2 \times V_{\text {int }}+\left|\mathrm{E}_{\text {fermi }}\right|$ and determines the minimum binding energy of the electrons that will be effective in scattering photoelectrons. Thus, only the deeper localised valence band electrons give rise to AXAFS scattering. See ref. [10]: D. C. Koningsberger, J. de Graaf, B. L. Mojet, D. E. Ramaker, J. T. Miller, Appl. Catal. A 2000, 191, 205.

[36] B. M. Weckhuysen, L. M. de Ridder, R. A. Schoonheydt, J. Phys. Chem. 1993, 97, 4756-4763.

[37] B. M. Weckhuysen, R. A. Schoonheydt, Catal. Today 1999, 49, 441451.

[38] F. W. H. Kampers, T. M. J. Maas, J. van Grondelle, P. Brinkgreve, D. C. Koningsberger, Rev. Sci. Instrum. 1989, 60, 2635-2638.

[39] M. Vaarkamp, J. C. Linders, D. C. Koningsberger, Physica $B+C$ 1995, 208/209, 159.

[40] M. Tromp, J. A. van Bokhoven, A. M. Arink, J. H. Bitter, G. van Koten, D. C. Koningsberger, Chem. Eur. J. 2002, 8, 5667-5678.

[41] M. Tromp, J. A. van Bokhoven, R. J. van Haaren, G. P. F. van Strijdonck, A. M. J. van der Eerden, P. W. N. M. van Leeuwen, D. C. Koningsberger, J. Am. Chem. Soc. 2002, 124, 14814-14815.

[42] Cerius², Molecular Simulations Inc., San Diego, 1997.

[43] R.-S. Zhou, R. L. Snyder, Acta Crystallogr. Sect. B 1991, 47, 617630.

[44] A. W. Stobbe-Kreemers, G. C. van Leerdam, J.-P. Jacobs, H. H. Brongersma, J. J. F. Scholten, J. Catal. 1995, 152, 130-136.

[45] A. Khodakov, B. Olthof, A. T. Bell, E. Iglesia, J. Catal. 1999, 181, 205-216.

Received: August 3, 2006

Revised: January 5, 2007 Published online: April 20, 2007 